\title{
Predictive Value of Positive Surgical Margins after Radical Prostatectomy for Lymph Node Metastasis in Locally Advanced Prostate Carcinoma
}

\author{
Wolfgang Otto, Peter Gerber, Wolfgang Rößler, Wolf F. Wieland, and Stefan Denzinger \\ Department of Urology, St. Josef Medical Centre, University of Regensburg, Landshuter Straße 65, 93053 Regensburg, Germany \\ Correspondence should be addressed to Wolfgang Otto, wolfgang.otto@klinik.uni-regensburg.de
}

Received 1 July 2011; Accepted 4 August 2011

Academic Editor: Maximilian Burger

Copyright () 2012 Wolfgang Otto et al. This is an open access article distributed under the Creative Commons Attribution License, which permits unrestricted use, distribution, and reproduction in any medium, provided the original work is properly cited.

\begin{abstract}
Introduction. Suspected locally advanced prostate carcinoma shows lymph node involvement in a high percentage of cases. For a long time, such patients were not radically prostatectomised. In recent years, however, this viewpoint has changed. Material and Methods. We analysed a single-centre series of 34 patients with suspected locally advanced prostate cancer to establish predictive parameters for lymph node metastasis. All patients underwent radical prostatectomy between 2007 and 2010. Results. Of the 34 patients, 26\% showed pathological stage T3a, 59\% pT3b, and 15\% pT4. Median preoperative PSA level was $25 \mathrm{ng} / \mathrm{mL}$, and five patients had had neoadjuvant antihormonal treatment. Positive margins were found in $76 \%$ of patients. Patients without neoadjuvant treatment showed it in $79 \%$, and after preoperative antihormonal treatment the rate was $60 \%$. Positive margins were associated with lymph node involvement in $85 \%$ of cases, complete resection was associated only in $50 \%$ of cases. Conclusions. Positive surgical margins play an important predictive role when estimating lymph node involvement in patients with locally advanced prostate carcinoma. Neoadjuvant antihormonal therapy is associated with a relevant reduction in the rate of positive margins but not with the rate of lymph node metastasis. As such, a combination of antihormonal and surgical treatment should be considered.
\end{abstract}

\section{Introduction}

According to the European Association of Urology (EAU) guidelines on prostate carcinoma, radical prostatectomy (RP) is the standard treatment for stage T2N0M0 prostate cancer, equivalent to radiation therapy. For locally advanced prostate cancer, recommendations are less concise. In selected patients RP in combination with extended pelvic lymphadenectomy may be feasible. A study by Gontero et al. showed no relevant differences in the rate of comorbidities, only transfusion and lymphocele rate appeared more often compared to T2N0M0 prostate carcinoma. Cancer-specific survival (CSS) was 90\% for T3-4, N0, M0 prostate cancer, and $99 \%$ for organ-confined cancer [1].

In lymph node positive prostate cancer after RP and adjuvant hormonal treatment 10 -year CSS reaches $80 \%$ [2]. However, known lymph node metastasis remains a contraindication for most urologists for radical prostatectomy, and antihormonal treatment is initiated. Since then, the standing of radical prostatectomy as a treatment in this indication has been promoted by the findings of Engel et al., even in cases of suspected or proven lymph node metastasis. They were able to show that the survival of patients with lymph node metastasis was improved by radical prostatectomy when compared to patients who broke off surgery [3]. Adjuvant radiotherapy combined with hormonal treatment in lymph node involvement is advantageous when compared with hormonal treatment alone [4]. Preoperative prediction of lymph node involvement is challenging, especially in current-era prostate cancer with high percentage of low-risk prostate carcinoma that do not fit with the Roach formula, which overpredicts lymph node metastasis $[5,6]$.

We analysed a single-centre collective of patients suspected for $\geq \mathrm{cT} 3$ prostate carcinoma after radical prostatectomy and pelvic lymphadenectomy in order to establish the predictability of lymph node involvement by virtue of histopathological parameters. 


\section{Material and Methods}

We retrospectively collected clinical and histopathological data of 34 patients who underwent RP for suspected $\geq \mathrm{cT} 3$ prostate cancer. Open surgery took place between 2007 and 2010 in a German single centre.

Suspect digital rectal examination (DRE), elevated PSA level, lower urinary tract symptoms (LUTS) or hydronephrosis led to the suspicion of prostate cancer, respectively. Diagnosis was assessed by ultrasound-guided prostate biopsy. Locally advanced stage was indicated by suspect digital rectal examination and confirmed by computed tomography (CT). There was no evidence of lymph node involvement or organ metastasis in CT assessment. Before surgical therapy all patients underwent bone scans without detection of skeletal metastasis. To reduce local tumour mass, five patients were neoadjuvantly treated antihormonally.

We assessed $\mathrm{pT}$ and $\mathrm{pN}$ stage, the share of positive margins (R1) and compared bioptic and specimen Gleason scores as well as the predictive value of these parameters with regard to the existence of lymph node metastasis.

\section{Results and Discussion}

3.1. Clinical and Histopathological Patient Data. 34 patients with a median age of 65 years (range 55-75 years) and with suspected locally advanced prostate carcinoma had a median PSA level of $23 \mathrm{ng} / \mathrm{mL}$ (range $5-141 \mathrm{ng} / \mathrm{mL}$ ) at the time of diagnosis. The day prior to surgery median PSA level was $25 \mathrm{ng} / \mathrm{mL}$, but some patients only had one PSA testing run before surgery. Four out of five patients who underwent neoadjuvant antihormonal therapy had no further preoperative PSA testing; one patient's PSA level decreased from 98 to $2 \mathrm{ng} / \mathrm{mL}$.

The median Gleason score from the prostate biopsy was 8 (range 6-10) and from the prostatectomy specimen 9 [7-9]. Only in 44\% Gleason score of prostate biopsy and specimen was identical; underestimation in prostate biopsy score of one to three points was detected in $41 \%$ of patients and overestimation of one score point in $15 \%$. Patients showed pathological stage pT3a in 26\%, pT3b in 59\% and pT4 in $15 \%$. For details see Table 1 . Residual tumour defined by cancer positive margin of the prostatectomy specimen was found in $76 \%$. Neoadjuvant treatment seemed to have a protective effect, with positive margins in $60 \%$ of these patients whilst patients without preoperative antihormonal therapy showed residual tumour in $79 \%$ of cases. Whilst $85 \%$ of patients with positive margins had lymph node metastasis, only $50 \%$ of the patients without residual prostate tumour mass showed lymph node involvement (Table 2). Median number of dissected lymph nodes was 15 (range 6-32), in the case of lymph node metastasis, and the median number of metastasis was 2 (range 1-10).

3.2. Discussion of Predictive Factors for the Existence of Lymph Node Metastasis. In a multicentre series of 712 patients, Spahn et al. showed that PSA levels $>20 \mathrm{ng} / \mathrm{mL}$ were associated with organ-confined tumour in $33 \%$, with Gleason score $\leq 6$ in prostate biopsy in $8 \%$, with negative surgical
TABLE 1: Characteristics of patients with locally advanced prostate carcinoma.

\begin{tabular}{|c|c|c|c|c|c|c|}
\hline No. & Age & PSA & GS biopsy & GS specimen & pT stage & pN stage \\
\hline 1 & 60 & 77,3 & 6 & 7 & pT3b & $\mathrm{pN} 1$ \\
\hline 2 & 66 & 36,0 & 6 & 7 & pT3a & $\mathrm{pN} 1$ \\
\hline 3 & 68 & 30,2 & 6 & 7 & pT3a & $\mathrm{pN} 1$ \\
\hline 4 & 62 & 58,0 & 6 & 8 & pT3b & pNo \\
\hline 5 & 64 & 35,6 & 6 & 9 & pT3a & $\mathrm{pN} 0$ \\
\hline 6 & 59 & 60,0 & 6 & 9 & pT3b & $\mathrm{pN} 1$ \\
\hline 7 & 60 & 31,5 & 7 & 7 & pT3b & $\mathrm{pN} 1$ \\
\hline 8 & 65 & 52,0 & 7 & 7 & pT3b & $\mathrm{pN} 1$ \\
\hline 9 & 70 & 56,0 & 7 & 7 & pT3b & $\mathrm{pN} 1$ \\
\hline 10 & 74 & 17,8 & 7 & 8 & pT3b & $\mathrm{pN} 0$ \\
\hline 11 & 63 & 21,4 & 7 & 8 & pT3b & $\mathrm{pN} 1$ \\
\hline 12 & 75 & 14,2 & 7 & 9 & pT3b & $\mathrm{pN} 1$ \\
\hline 13 & 55 & 5,8 & 7 & 9 & pT4 & $\mathrm{pN} 0$ \\
\hline 14 & 61 & 100,0 & 7 & 9 & pT3a & $\mathrm{pN} 0$ \\
\hline 15 & 63 & 14,1 & 7 & 9 & pT4 & $\mathrm{pN} 1$ \\
\hline 16 & 62 & 47,0 & 8 & 7 & pT3b & $\mathrm{pN} 1$ \\
\hline 17 & 74 & 23,3 & 8 & 7 & pT3a & $\mathrm{pN} 1$ \\
\hline 18 & 63 & 73,0 & 8 & 8 & pT3b & $\mathrm{pN} 1$ \\
\hline 19 & 68 & 11,5 & 8 & 8 & pT3a & pN0 \\
\hline 20 & 71 & 15,2 & 8 & 8 & pT3a & pNo \\
\hline 21 & 70 & 9,5 & 8 & 8 & pT3b & $\mathrm{pN} 1$ \\
\hline 22 & 71 & 141,0 & 8 & 9 & pT3b & $\mathrm{pN} 1$ \\
\hline 23 & 65 & 138,0 & 8 & 9 & pT4 & $\mathrm{pN} 1$ \\
\hline 24 & 64 & 34,7 & 9 & 8 & pT4 & pN1 \\
\hline 25 & 70 & 7,2 & 9 & 9 & pT3a & $\mathrm{pN} 1$ \\
\hline 26 & 69 & 14,6 & 9 & 9 & pT3b & $\mathrm{pN} 1$ \\
\hline 27 & 60 & 13,0 & 9 & 9 & pT3b & $\mathrm{pN} 1$ \\
\hline 28 & 70 & 100,0 & 9 & 9 & pT3b & $\mathrm{pN} 1$ \\
\hline 29 & 58 & 25,0 & 9 & 9 & pT3a & pN0 \\
\hline 30 & 67 & 100,0 & 9 & 9 & pT3b & $\mathrm{pN} 1$ \\
\hline 31 & 61 & 22,0 & 9 & 9 & pT3b & $\mathrm{pN} 1$ \\
\hline 32 & 68 & 2,2 & 9 & 9 & pT3b & $\mathrm{pN} 1$ \\
\hline 33 & 56 & 15,1 & 10 & 9 & pT3b & $\mathrm{pN} 1$ \\
\hline 34 & 70 & 15,0 & 10 & 9 & pT4 & $\mathrm{pN} 1$ \\
\hline
\end{tabular}

GS: Gleason score.

margins in 54\%, and with no lymph node involvement in $85 \%$ of cases, respectively [7]. Patients with PSA levels $>20 \mathrm{ng} / \mathrm{mL}$ and suspected locally advanced prostate cancer had positive margins in $79 \%$ and lymph node invasion in $51 \%$ of cases. Our results confirmed these findings by showing residual tumour and lymph node metastasis in $76 \%$ of cases. Using the same series, Gontero et al. found that the PSA level was of prognostic relevance with $26 \%$ cured by surgery alone when PSA was $20-50 \mathrm{ng} / \mathrm{mL}$ but only about 7$9 \%$ with PSA $>50 \mathrm{ng} / \mathrm{mL}$ [8]. A single-centre analysis of more than 2600 patients with locally advanced prostate cancer after RP and adjuvant androgen deprivation revealed the Gleason score to be the most important prognostic factor [9]. In our much smaller series we did not attempt to show cancer-specific survival, but for the prediction of T stage and 
TABLE 2: Association of positive margins with lymph node metastasis.

\begin{tabular}{|c|c|c|c|c|}
\hline No. & Age & Neoadj. HT & R stage & pN stage \\
\hline 1 & 60 & No & $\mathrm{R} 1$ & $\mathrm{pN} 1$ \\
\hline 2 & 66 & No & $\mathrm{R} 1$ & $\mathrm{pN} 1$ \\
\hline 3 & 68 & No & $\mathrm{R} 1$ & $\mathrm{pN} 1$ \\
\hline 4 & 62 & No & $\mathrm{R} 1$ & $\mathrm{pN} 0$ \\
\hline 5 & 64 & No & R0 & pN0 \\
\hline 6 & 59 & No & $\mathrm{R} 1$ & $\mathrm{pN} 1$ \\
\hline 7 & 60 & Yes & R0 & $\mathrm{pN} 1$ \\
\hline 8 & 65 & No & $\mathrm{R} 1$ & $\mathrm{pN} 1$ \\
\hline 9 & 70 & No & $\mathrm{R} 1$ & $\mathrm{pN} 1$ \\
\hline 10 & 74 & No & R0 & $\mathrm{pN} 0$ \\
\hline 11 & 63 & No & $\mathrm{R} 1$ & $\mathrm{pN} 1$ \\
\hline 12 & 75 & No & $\mathrm{R} 1$ & $\mathrm{pN} 1$ \\
\hline 13 & 55 & No & $\mathrm{R} 1$ & $\mathrm{pN} 0$ \\
\hline 14 & 61 & Yes & $\mathrm{R} 1$ & $\mathrm{pN} 0$ \\
\hline 15 & 63 & No & $\mathrm{R} 1$ & $\mathrm{pN} 1$ \\
\hline 16 & 62 & Yes & R0 & $\mathrm{pN} 1$ \\
\hline 17 & 74 & No & R0 & $\mathrm{pN} 1$ \\
\hline 18 & 63 & No & $\mathrm{R} 1$ & $\mathrm{pN} 1$ \\
\hline 19 & 68 & No & R0 & pNo \\
\hline 20 & 71 & No & R0 & pNo \\
\hline 21 & 70 & No & $\mathrm{R} 1$ & $\mathrm{pN} 1$ \\
\hline 22 & 71 & No & $\mathrm{R} 1$ & $\mathrm{pN} 1$ \\
\hline 23 & 65 & No & $\mathrm{R} 1$ & $\mathrm{pN} 1$ \\
\hline 24 & 64 & No & $\mathrm{R} 1$ & $\mathrm{pN} 1$ \\
\hline 25 & 70 & No & R0 & $\mathrm{pN} 1$ \\
\hline 26 & 69 & No & $\mathrm{R} 1$ & $\mathrm{pN} 1$ \\
\hline 27 & 60 & No & $\mathrm{R} 1$ & $\mathrm{pN} 1$ \\
\hline 28 & 70 & Yes & $\mathrm{R} 1$ & $\mathrm{pN} 1$ \\
\hline 29 & 58 & No & $\mathrm{R} 1$ & pN0 \\
\hline 30 & 67 & No & $\mathrm{R} 1$ & $\mathrm{pN} 1$ \\
\hline 31 & 61 & No & $\mathrm{R} 1$ & $\mathrm{pN} 1$ \\
\hline 32 & 68 & Yes & $\mathrm{R} 1$ & $\mathrm{pN} 1$ \\
\hline 33 & 56 & No & $\mathrm{R} 1$ & $\mathrm{pN} 1$ \\
\hline 34 & 70 & No & $\mathrm{R} 1$ & $\mathrm{pN} 1$ \\
\hline
\end{tabular}

HT: antihormonal treatment.

lymph node involvement, the Gleason score was not the most obvious parameter. Evidence of residual tumour presence on the surgical margins in our patient collective was the most important predictive parameter for lymph node metastasis. $76 \%$ positive margins corresponded with $76 \%$ stage $\mathrm{pN} 1$. Patients with positive margins had synchronous lymph node metastasis in $85 \%$, and negative margins were only associated in $50 \%$ with lymph node metastasization. Another study on a collective of high-risk prostate cancer (stage $\geq$ pT3 in 89\%) showed positive margins in $83 \%$ but only in $28 \% \mathrm{pN} 1$ disease [10]. Oh et al. showed that positive margins in stage pT2 prostate cancer lead to a worse outcome, similar to that of patients with locally advanced prostate carcinoma [11].

\section{Conclusions}

Alongside the Gleason score and pathological $\mathrm{T}$ stage, the presence of positive surgical margins is an important predictive factor in estimating lymph node involvement. Neoadjuvant antihormonal therapy does lead to a relevant reduction in the rate of positive margins, but not to a reduction in the rate of lymph node metastasis. As such, antihormonal and surgical treatment should be considered in combination for the therapy of locally advanced prostate cancer.

\section{References}

[1] P. Gontero, G. Marchioro, R. Pisani et al., "Is radical prostatectomy feasible in all cases of locally advanced non-bone metastatic prostate cancer? Results of a single-institution study," European Urology, vol. 51, no. 4, pp. 922-930, 2007.

[2] R. Ghavamian, E. J. Bergstralh, M. L. Blute, J. Slezak, and H. Zincke, "Radical retropubic prostatectomy plus orchiectomy versus orchiectomy alone for $\mathrm{pTxN}+$ prostate cancer: a matched comparison," Journal of Urology, vol. 161, no. 4, pp. 1223-1228, 1999.

[3] J. Engel, P. J. Bastian, H. Baur et al., "Survival benefit of radical prostatectomy in lymph node-positive patients with prostate cancer," European Urology, vol. 57, no. 5, pp. 754-761, 2010.

[4] L. F. Da Pozzo, C. Cozzarini, A. Briganti et al., "Longterm follow-up of patients with prostate cancer and nodal metastases treated by pelvic lymphadenectomy and radical prostatectomy: the positive impact of adjuvant radiotherapy," European Urology, vol. 55, no. 5, pp. 1003-1011, 2009.

[5] M. Roach III, C. Marquez, H. S. Yuo et al., "Predicting the risk of lymph node involvement using the pre-treatment prostate specific antigen and Gleason Score in men with clinically localized prostate cancer," International Journal of Radiation Oncology Biology Physics, vol. 28, no. 1, pp. 33-37, 1994.

[6] S. Rahman, H. Cosmatos, G. Dave, S. Williams, and M. Tome, "Predicting pelvic lymph node involvement in current-era prostate cancer," International Journal of Radiation Oncology. In press.

[7] M. Spahn, S. Joniau, P. Gontero et al., "Outcome predictors of radical prostatectomy in patients with prostate-specific antigen greater than $20 \mathrm{ng} / \mathrm{ml}$ : a European multi-institutional study of 712 patients," European Urology, vol. 58, no. 1, pp. 17, 2010.

[8] P. Gontero, M. Spahn, B. Tombal et al., "Is there a prostatespecific antigen upper limit for radical prostatectomy?" British Journal of Urology International. In press.

[9] M. Spahn, C. Weiss, P. Bader et al., "Long-term outcome of patients with high-risk prostate cancer following radical prostatectomy and stage-dependent adjuvant androgen deprivation," Urologia Internationalis, vol. 84, no. 2, pp. 164-173, 2010.

[10] S. S. Connolly, S. F. Oon, C. Carroll et al., "Radical prostatectomy outcome when performed with PSA above $20 \mathrm{ng} / \mathrm{ml}$," Irish Medical Journal, vol. 104, no. 4, pp. 108-111, 2011.

[11] J. J. Oh, S. K. Hong, S. S. Byun, G. Choe, and S. E. Lee, "Prognostic significance of positive surgical margins after radical prostatectomy among pT2 and pT3a prostate cancer," Urologic Oncology. In press. 


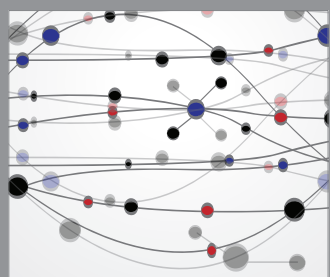

The Scientific World Journal
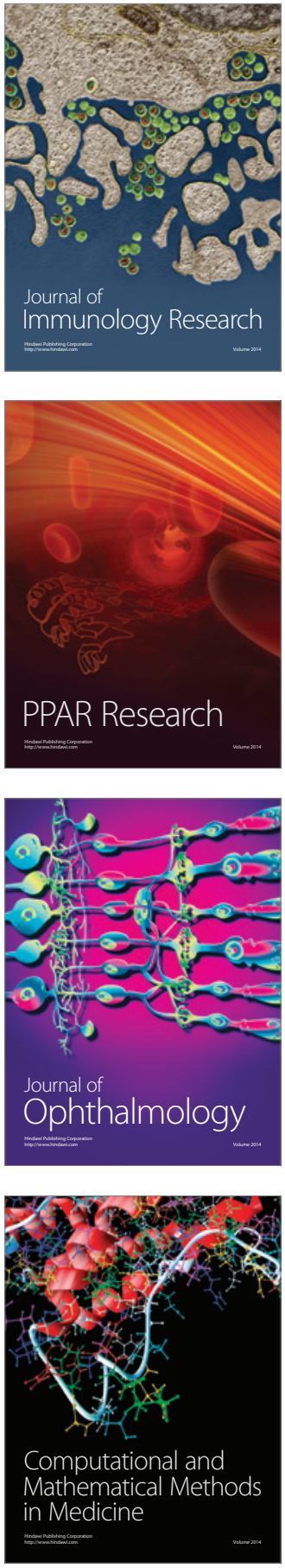

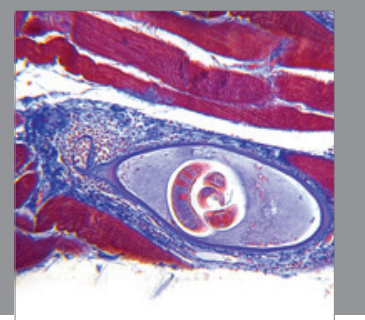

Gastroenterology

Research and Practice
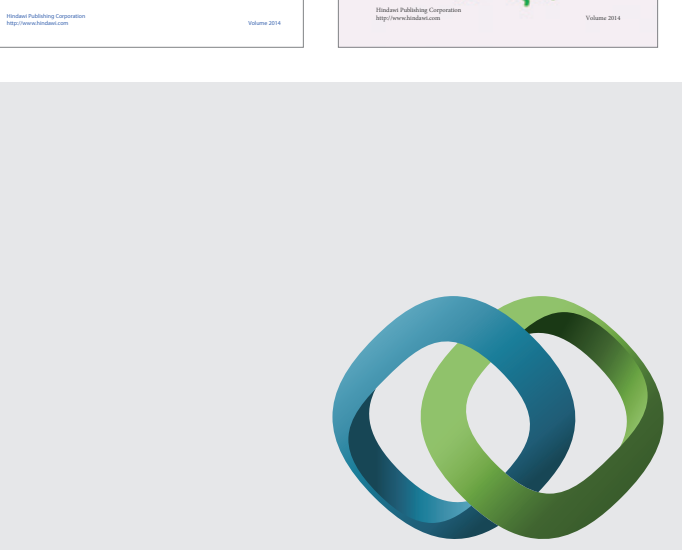

\section{Hindawi}

Submit your manuscripts at

http://www.hindawi.com
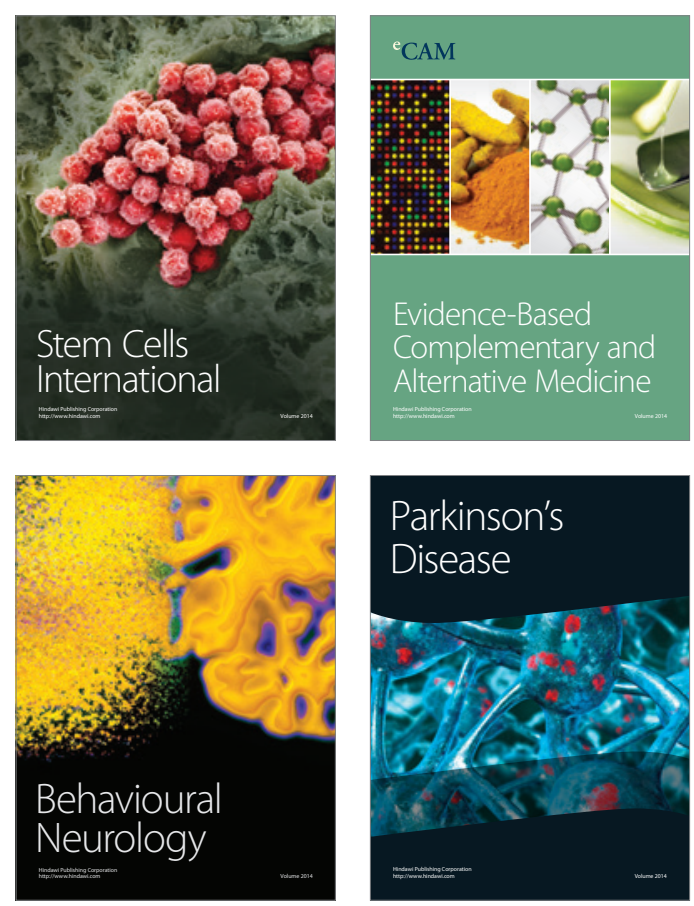

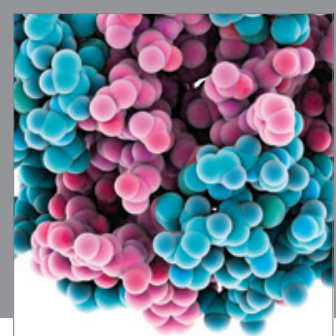

Journal of
Diabetes Research

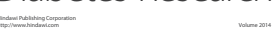

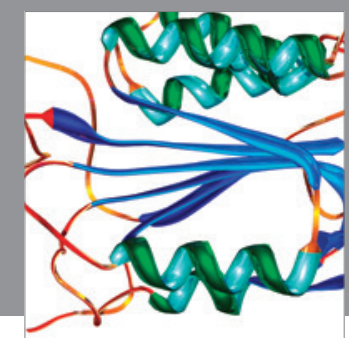

Disease Markers
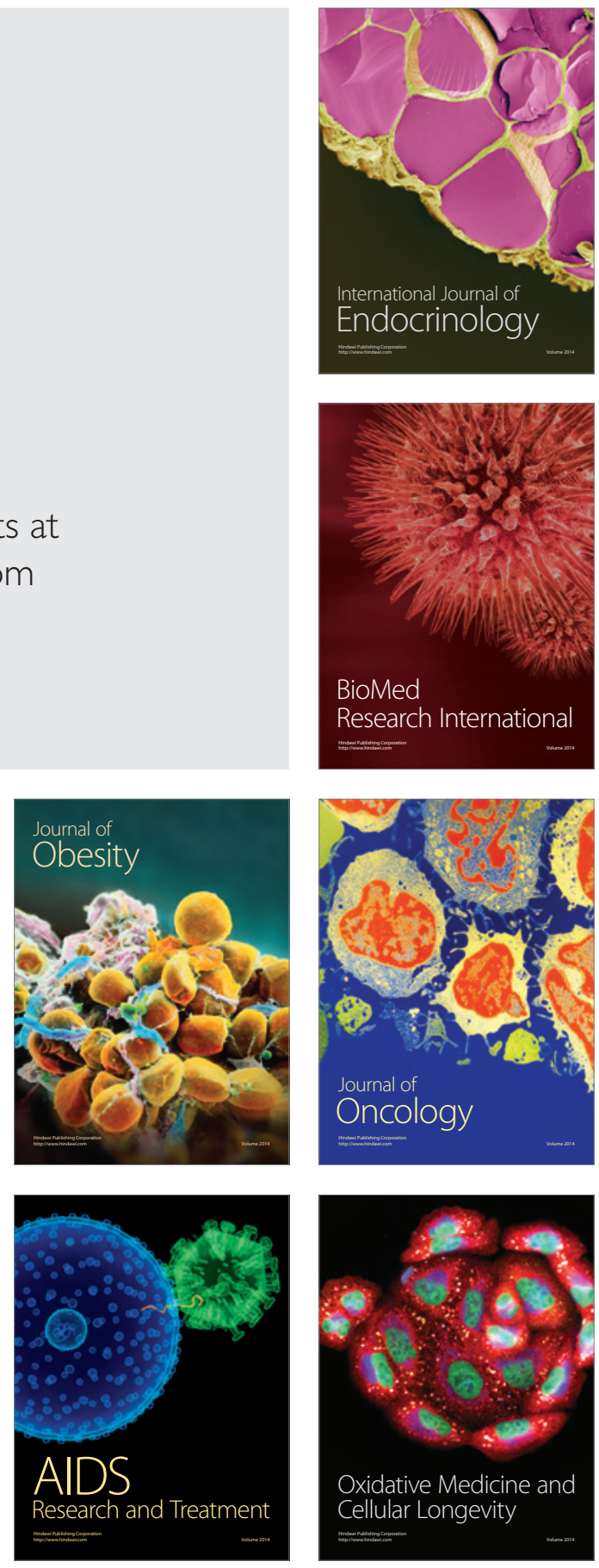